\title{
Study on Fairness of Secondary Vocational Education Funding in China
}

\author{
Man Kong \\ Department of Education Management, East China Normal University, Shanghai, China \\ Email address: \\ 1107522769@qq.com \\ To cite this article: \\ Man Kong. Study on Fairness of Secondary Vocational Education Funding in China. Science Journal of Education. \\ Vol. 6, No. 1, 2018, pp. 17-21. doi: 10.11648/j.sjedu.20180601.13
}

Received: January 25, 2018; Accepted: February 22, 2018; Published: March 9, 2018

\begin{abstract}
Under the condition of limited education resources in China, while reforming the financial system of secondary vocational education, the investment in education faces a fair crisis. The issue of fairness is mainly manifested in two aspects: The economic status of secondary vocational education is low, and the regional investment in secondary vocational education is not balanced. To solve these problems, the Chinese government should gradually improve the status of secondary vocational education. In addition, government's investment should play a major role in secondary vocational education. The Chinese government should speed up the formulation and implementation of funding standards for secondary vocational education and encourage social forces to step up secondary vocational education investment.
\end{abstract}

Keywords: Secondary Vocational Education, Funding, Education Expenditure, Education Fairness

\section{Introduction}

Education fairness, as an extension and embodiment of social equity value in education, is not only the basic goal of education modernization but also an important cornerstone of social justice. Vocational education is a real sense of inclusive education, compared with the same level of general education, its inclusiveness stronger, as compensation education for disadvantaged groups, in the aspect of eliminating education inequality has unique value, is the effective way of the compensation for the vulnerable groups to education and means [1]. For those with or without school education, vocational education can be offered by vocational training with a more suitable and easy way to master the knowledge and skills about modern social life and production. Professional education is the material premise for the development of education. However, there is a fair crisis in the investment of education. Currently in China, ordinary primary and secondary schools, undergraduate colleges and vocational colleges all have established a nationwide appropriate system for funding, only secondary vocational schools are not perfect. Therefore, while increasing investment in education, it is necessary to establish a stable financial funding mechanism. This system should not only meet the basic needs of the development of secondary vocational schools, but also can play a leading role in fiscal funds. This is a key measure for vocational education reformation and fair development [2]. It shows that under the concept of "education fairness", studying the funding of secondary vocational education will help people to change their prejudices against vocational education and encourage society to be more concerned about and support the development of vocational education. The government should also formulate a more fair fiscal policy for secondary vocational education and promote the sustainable development of secondary vocational education.

\section{The Development Status of Education in China}

Since 2005 , secondary vocational education is not only the important characteristics of regional balanced development, but also made a positive contribution in promoting regional between high school education equality of opportunity, human resources structure optimization and balancing urban and rural dual structure [3]. Starting from the autumn semester of 2009, China exempted tuition fees for students from economically disadvantaged rural families and agriculture-related majors in secondary vocational schools. In other words, secondary vocational education as a basic and inclusive education 
services will be included in the basic public education services, which not only can effectively reduce the cost of school attendance and education services, and stimulate education demands in poor areas, which but also can achieve the purpose of the government to develop secondary vocational education[4].

\subsection{The Scale of Education Continues to Expand}

In recent ten years, with the increasing financial input by the government in secondary vocational education, the scale of education is also constantly expanding. By 2010, the number of students enrolled in schools has reached 22.385 million. The proportion of secondary education in senior secondary education has continuously increased, accounting for almost half of China's high school education. At the same time, the number of teachers has increased by 129,700 in the last five years, all of which indicate that more and more people are investing in the construction of secondary vocational education.

\subsection{Education Returns on Investment Are on the Rise}

Since 2000 , there are many research findings have shown that the return on investment of rural secondary vocational education shows an upward trend. Zhou Yahong (2010) conducted an analysis using 416 household survey data from 3 rural counties in 2007 in rural China. The results showed that rural vocational education had a significant impact on household income of rural households. The three-year total return rate of rural vocational education was $27 \%$, Average annual rate of return of 9\%. Li Hongbin\&Zhang Junsen (2008) found that the investment return rate of urban vocational high school education was significantly higher than that of general senior secondary education. The regression results show that the return on investment of vocational education is between $32.4 \%$ and 34.4\%. Hu Yongmei \& Chen Chunhua (2013) established the regression model through the method of "propensity score matching", and found that the economic benefits for those who received vocational education were significantly higher than that of ordinary senior high school education practitioners in the same age group [5]. Some scholars also carried out a sample follow-up analysis on 1993 graduates of 6 secondary vocational schools and 6 general high schools in Hunan Province of China. They found that the employment conditions of job seekers are different from those of their job satisfaction, job number, unemployment time and working environment In terms of indicators, the non-monetary gains of secondary vocational and technical personnel are significantly higher than those of high school [6].

All these studies have revealed a common conclusion that vocational education is devoted to cultivating social talents with certain professional knowledge and professional expertise, which are important for developing the local economy and enhancing the individual qualities of workers and improving the quality of life of ordinary families effect.

\section{Fairness Issues in Secondary Vocational Education Funding}

The funding of secondary vocational education is the material premise for the secondary vocational education development. At this stage, the fairness issues of Chinese secondary vocational education mainly involved the following three aspects: First, secondary vocational education in the education system in the low economic status. Second, secondary vocational education sources of funding structure is irrational. Third, the regional investment in secondary vocational education is not balanced.

\subsection{The Economic Status of Secondary Vocational Education Is Low}

Although the total amount of funding for secondary vocational education in China has been increasing year by year, its proportion in the entire education funding system is low, and the funding for secondary vocational education in the whole country is insufficient to meet the needs of the development of education [7]. The lower status of secondary vocational education in the entire education system is manifested in the following three aspects.

First of all, the funding for secondary vocational education is relatively inadequate. One study shows that the average student expenditure in vocational schools in developing countries is generally 1.5 times higher than that of ordinary secondary schools [8]. Although China has continuously raised its financial allocations for secondary vocational education in recent years, the gap between the funding for secondary vocational education and that of ordinary senior secondary schools has been gradually decreasing. However, the unbalanced education finance in China has persisted and is very serious, as shown in Table 1. The data from 2007 to 2011 show that the investment in secondary vocational education is only $66.7 \%$ of that of ordinary high schools. Thus it can be seen that the investment of secondary vocational education is far lower than that of ordinary senior secondary education and the investment is relatively insufficient. This also shows that secondary vocational education has a low status in the education system and can not get the fair treatment.

Table 1. Comparison of Educational Funds between Secondary Vocational School and Ordinary High School Students in 2008- 2015 (Unit:100 million RMB).

\begin{tabular}{|c|c|c|c|c|c|c|c|c|}
\hline Years & 2008 & 2009 & 2010 & 2011 & 2012 & 2013 & 2014 & 2015 \\
\hline Ordi & 689 & 837 & 985 & 117 & 123 & 145 & 160 & 170 \\
\hline nary High School & 91 & 89 & 37 & 5.86 & 7.64 & 9.41 & 8.23 & 2.11 \\
\hline Secondary Vocational School & 440.88 & 585.55 & 708.62 & 832.52 & 1037.92 & 1282.63 & 1412.43 & 1659.32 \\
\hline
\end{tabular}

Source: Statistical Yearbook of Educational Funds in China, 2009-2016. 
Secondly, the proportion of secondary vocational education in education funding is relatively low. As can be seen from Table 2, as far as funding for secondary vocational education is concerned, its share of the national financial education expenditure has never exceeded $6.8 \%$ in 2007-2011, compared with 3 to 4 times in developed countries. In 2011, the entire vocational education accounted for $12.1 \%$ of the national education fund, whereas the international practice considers that the proportion of vocational education funds in the national education input should be $25 \%$ and the high standard is $35 \%$ [9]. In 1998, A World Bank study found that vocational education in developing countries generally costs $153 \%$ more than average secondary schools. This is because vocational education not only requires the same teaching conditions as general education, such as classrooms and multimedia teaching facilities, but also training bases, experimental facilities and a large amount of hardware costs. This shows that at this stage China's occupation education funding is still far below the international standards, can not follow the scale of vocational education growth and the level of increased demand. This is also a manifestation of the unfair treatment of secondary vocational education as a whole.

Table 2. Proportion of Secondary Education Funds in Nationwide Educational Funds (\%).

\begin{tabular}{|c|c|c|c|c|c|}
\hline Years & 2007 & 2008 & 2009 & 2010 & 2011 \\
\hline National Financial Funds for Education (Unit:Yuan RMB) & 82802142 & 104496296 & 122310935 & 146700670 & 185867009 \\
\hline Financial Funds for Education in Secondary Vocational schools (Unit:Yuan RMB) & 5121957 & 6822714 & 8141848 & 9682826 & 12590644 \\
\hline Proportion & $6.19 \%$ & $6.53 \%$ & $6.66 \%$ & $6.60 \%$ & $6.77 \%$ \\
\hline
\end{tabular}

Source: China national bureau of statistics.

Thirdly, the structure of funding sources for secondary vocational education is irrational. In China, the sources of financing for education mainly come from the following five channels: State financial education funds, operating expenses, funds for social organizations and individual citizens, funds donated by the society, and other funds for education. However, the financing method for secondary vocational education is relatively simple, most of which comes from the state financial education investment and career income in two parts, of which the main business income is tuition and miscellaneous fees. In 2011, the funding for secondary vocational education in the country totaled $93.13 \%$ of the state's financial education expenditure and career income. Due to the government's relatively strong subsidy policy, tuition fees for students have dropped but still accounted for $16.29 \%$. This situation shows that the source of vocational education funding is relatively simple and the total input is insufficient. In particular, the performance of social groups is not strong support, although vocational education and training of skilled personnel directly serve the social development, but few enterprises have invested in secondary vocational schools, Chinese society blind pursuit of highly educated also inhibited social forces on investment in vocational secondary schools[10]. In the case of insufficient government and social funding, the funds required for the normal operation of the school can only be borne by the students, which of course can not reflect the public welfare of secondary vocational education, and once again illustrates the unfair treatment suffered by secondary vocational education at this stage.

\subsection{The Regional Investment in Secondary Vocational Education Is Not Balanced}

A balanced allocation of funds for secondary vocational education is helpful to realize social fairness and promote social harmony and stability. At this stage, the funding for secondary vocational education in China presents a serious regional imbalance, which has a direct impact on the balanced development of secondary vocational education. There are great differences in the level of economic development among different regions in China. Such a localized system of running education will inevitably result in differences in the level of investment in vocational education across the country. As shown in Table 3, since the central region is not as developed as the eastern region and has no strong support from the central government as the western region, the central region has become the weak point in the development of vocational education. The phenomenon of "polarization" between the eastern and central regions is grave. The unhealthy development of secondary vocational education directly or indirectly affects the social and economic development in the region. Central provinces with less investment in secondary vocational education have plunged into a vicious cycle of slow industrial economic development, leading to more uneven regional development in China and more serious social equity issues.

Table 3. The secondary average education expenditure in Chinese province in 2011 (unit:yuan).

\begin{tabular}{|c|c|c|c|c|c|c|c|}
\hline \multicolumn{2}{|l|}{ Region } & \multirow{2}{*}{$\begin{array}{l}\text { Budget average expenditure } \\
19410.65\end{array}$} & \multirow{2}{*}{$\begin{array}{l}\text { Deviation } \\
11876.36\end{array}$} & \multicolumn{2}{|l|}{ Region } & \multirow{2}{*}{$\begin{array}{l}\text { Budget average expenditure } \\
6607.56\end{array}$} & \multirow{2}{*}{$\begin{array}{l}\text { Deviation } \\
-926.73\end{array}$} \\
\hline \multirow{7}{*}{$\begin{array}{l}\text { Eastern } \\
\text { Region }\end{array}$} & Beijing & & & \multirow{7}{*}{$\begin{array}{l}\text { Central } \\
\text { Region }\end{array}$} & Shanxi & & \\
\hline & Tianjin & 13409.42 & 5875.13 & & Jilin & 8778.32 & 1244.03 \\
\hline & Hebei & 4953.92 & -2581.29 & & Heilongjiang & 7213.01 & -321.28 \\
\hline & Liaoning & 8610.53 & 1076.24 & & Anhui & 4908.04 & -2626.25 \\
\hline & Shanghai & 15438.71 & 7904.42 & & Jiangxi & 6012.58 & -1521.71 \\
\hline & Jiangsu & 6215.22 & -1319.07 & & Henan & 5210.58 & -2323.71 \\
\hline & Zhejiang & 7961.9 & 427.61 & & Hubei & 3944.59 & -3589.7 \\
\hline
\end{tabular}




\begin{tabular}{|c|c|c|c|c|c|c|c|}
\hline Region & & Budget average expenditure & Deviation & Region & & Budget average expenditure & Deviation \\
\hline \multirow{7}{*}{$\begin{array}{l}\text { Western } \\
\text { region }\end{array}$} & Guangdong & 5435.21 & -2099.08 & \multirow{7}{*}{$\begin{array}{l}\text { Western } \\
\text { region }\end{array}$} & Sichuan & 5125.24 & -2409.05 \\
\hline & Hainan & 6541.24 & -993.05 & & Chongqing & 4962.05 & -2572.24 \\
\hline & & 6263.51 & -1270.78 & & Guizhou & 5211.49 & -2322.8 \\
\hline & Xinjiang & 10986.9 & 3452.61 & & Yunnan & 6702.81 & -831.48 \\
\hline & Guangxi & 6166.05 & -1368.24 & & Xizang & 12887.17 & -6246.12 \\
\hline & Gansu & 5402.07 & -2132.22 & & Neimenggu & 10700.86 & 3166.57 \\
\hline & Qinghai & 8799.44 & 1265.15 & & & & \\
\hline
\end{tabular}

Source: Statistical Yearbook of Educational Funds in China, 2011.

\section{Recommendations to Address Chines Secondary Vocational Education Funding Fair Issues}

In order to make the funds for secondary vocational education more just, we should try our best to improve the government in secondary vocational education and make great efforts in the following three aspects.

\subsection{Gradually Improve Secondary Vocational Education Status}

The development of secondary vocational education is in line with the needs of society. China now has a serious shortage of skilled personnel. Therefore, the development of secondary vocational education is urgent for China to train skilled personnel. In order to ensure the practical value of secondary vocational education can get the wide acceptance from all sectors of society, the relevant state departments should as soon as possible concern it in legal, the government should improve the corresponding legal security system then the adequacy of secondary vocational education finance is guaranteed [11]. In addition, the formation of social awareness is a long-term task and the government can improve the guiding measures on the personnel system and enterprise employment system, gradually establish the social status of technical personnel and gradually change China's traditional concept of "Emphasis on knowledge and neglect skills", and then making the society People from all walks of life agree and support the fair development of secondary vocational education in China [12].

\subsection{The Government should Play a Major Role in Secondary Vocational Education Investing}

Secondary vocational education as a "Semi-public goods", in addition to educated individuals and graduates can gain from it, the community is the largest beneficiary as graduates from secondary vocational education has made tremendous contributions for the development of the regional economy. According to the economic theory that "who benefits, who is responsible", the government is in duty bound to become a major investor in the secondary profession.

First of all, the government should increase its investment proportion in secondary vocational education. Government departments should make a reasonable adjustment of financial structure on the basis of comparing the cost differences between secondary vocational education and general senior secondary education in training qualified personnel, and increase the proportion of secondary vocational education funds investment can ensure secondary vocational education in the entire education system be equitably treated and be conducive to the sustainable development of education. In response, both central and provincial governments should step up their efforts to pay secondary vocational education funding and clarify the responsibilities that governments at all levels should shoulder in funding secondary vocational education.

Secondly, the funds investment should be different according to the regional economic level. Since the levels of economic development in the eastern, central and western regions are discrepant, the proportions of funds borne by governments at all levels should also be different. For the developed provinces and cities in the eastern region, the local government should be the main investment body. In the central region, it is advisable to make the central government as the main investor. For the backward areas in western China, establishing a sharing mechanism that the central government and the provincial government are both responsible will be the most appropriate means for education funding. Under this pluralistic mechanism, the sources of funds for secondary vocational education can be guaranteed, and schools in different levels of regions can also be balancedly developed. In the final analysis, adopting measures suiting local conditions is the only law for education fairness [13].

\subsection{Encourage Social Forces to Increase Investment in Secondary Vocational Education}

Although the government funding is the main funding source for secondary vocational education in China, the participation of social forces can not be ignored. After all, the government's fiscal investment has been extremely limited and can not keep pace with the growth of enrollment. The cost of education must be shared by multiple beneficiaries. Therefore, it is necessary to establish the cost-sharing mechanism of secondary vocational education and encourage social forces to participate in secondary vocational education. It will expand the sources of funding for education and fill the gaps in government financial support. As an important subject in the market economy, enterprises are the direct beneficiaries of the development of vocational education. To solve this problem, governments at all levels should formulate policies that encourage and guide enterprises to invest in vocational education and create a favorable environment for the cooperation between schools and enterprises. For schools, more proactive strategies can also be adopted, such as providing internship bases and internships for secondary 
vocational schools to establish long-term mechanism for school-enterprise cooperation.

\section{Conclusion}

Studying the funding of secondary vocational education under the concept of "education fairness"can helps us to correctly recognize the effect of secondary vocational education on social and economic development so as to promote the government to formulate a more equitable education and financial policy and ensure secondary vocational education can develop in a healthier circumstance. At present, the reform of vocational education in China must by meas of improving the funding input to stimulate the enthusiasm of the whole society to participate in the financing of vocational education and it is beneficial for us to change the long-time prejudice with vocational education in Chinese society. Making the government pay more attention to fairness in funding and regional resource allocation. It also can make contributions on the students in more disadvantaged areas.

\section{References}

[1] SU Hui, SUN Yi. Analysis on the Efficiency of Medium Vocational Education Fund Input in China - Based on DEA-BCC Model Evaluation [J]. Continuing Education Research, 2017 (11): 59-62.

[2] HE Xu, LI Ling. Study on the Current Situation, Problems and Countermeasures of Secondary Vocational Education Funding in China [J]. Journal of Inner Mongolia Normal University, Education Science Edition, 2015 (3).

[3] QI Zhan-yong, WANG Jia-xin. Logic and Future Trend of Vocational Education Policy Change in China [J]. Journal of East China Normal University (Education Science Edition), 2018,36 (01): 104.
[4] Shen Hong, Zhao Yonghui. "Getting Started" or "Going Free": The Choice of Free Vocational Education in Secondary Vocational Education [J]. Educational Research, 2014, (5).

[5] $\mathrm{Hu}$ Yongmei, Chen Chun-hsiu. Changes in the Return on Investment in Rural Vocational Education: $1989 \sim 2009$ [J]. Education and Economy, 2013 (1).

[6] LI Lan-lan. Comparison of Non-monetary Revenue between Secondary Vocational Education and Ordinary Senior High School Education [J]. Journal of Education Sciences, 2011, 27 (01): 14-20.

[7] Ministry of Education, National Bureau of Statistics of China Education Funding Statistical Yearbook [M]. Beijing: China Statistics Press, 2005-2012.

[8] ZHOU Fenghua. Study on the formulation, implementation and input modes of per student funding in secondary vocational education [J]China Vocational and Technical Education, 2012 (36): 5-10.

[9] Guo Guoxia, Xiang Caiyi, Pang Qing vocational education funding for financial security mechanism of construction $[\mathrm{J}]$. China Vocational and Technical Education, 2012 (12).

[10] Ma Shuchao, Zhang Chen, Chen Song. The Achievements, Problems and Countermeasures of the Balanced Development of Secondary Vocational Education [J]. Educational Research, 2011 (5): 52-57.

[11] ZHAO Ya-qin. Research on Development and Reform of Higher Education Financial Allocation Model [J]. Journal of Yangzhou University: Higher Education Study Edition, 2011 (3): 20-23.

[12] Huang Yongxiu. Study on the Guarantee Mechanism of the Integrated Development of Vocational Education in Urban and Rural Areas [J]. Vocational Education Forum, 2012 (3): 32-34.

[13] Ma Shuchao. Balanced Development of Regional Vocational Education [M]. Beijing: Science Press, 2011: 95-100. 